\title{
16. 活動性に対する成音の心理的㽎整について
}

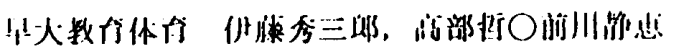

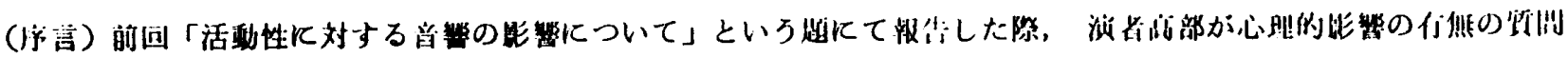
を受けたので，その後その点を即か道究した。

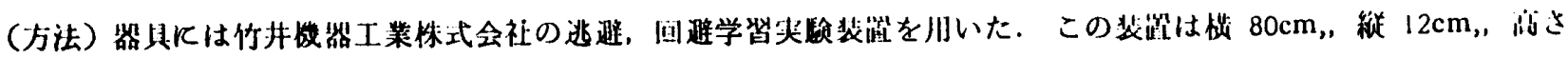

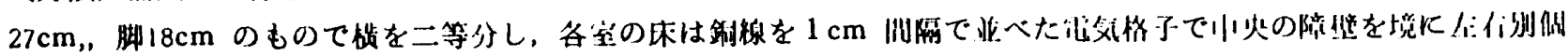

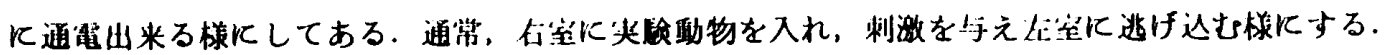

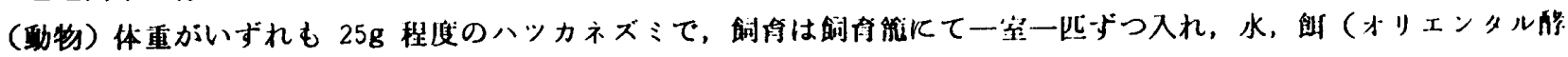

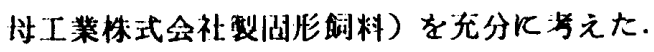

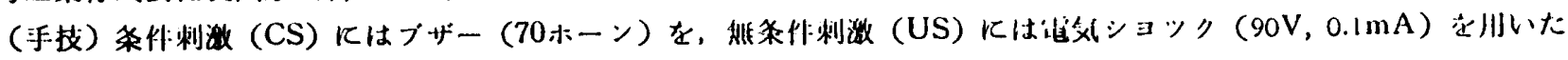

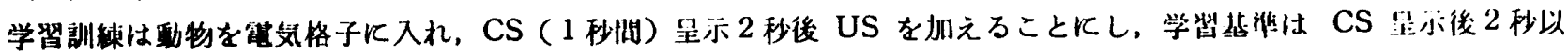

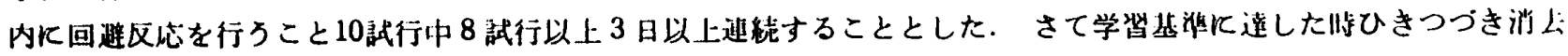

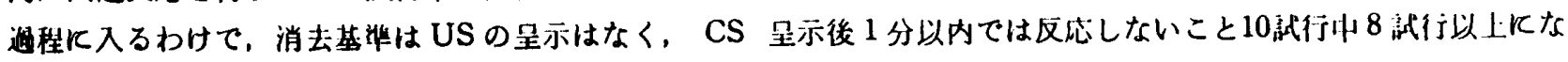
つた城合とした.

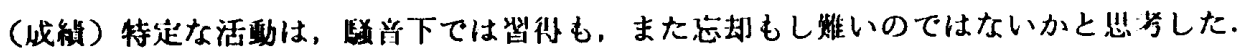

\section{7. 更動選手の Body Image}

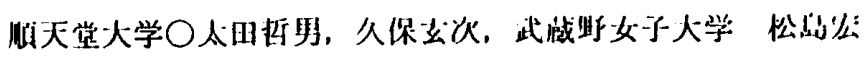

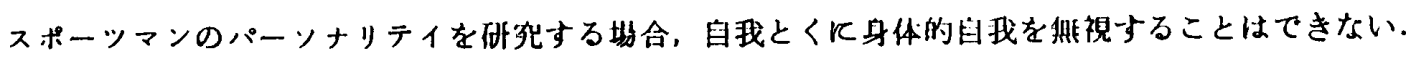

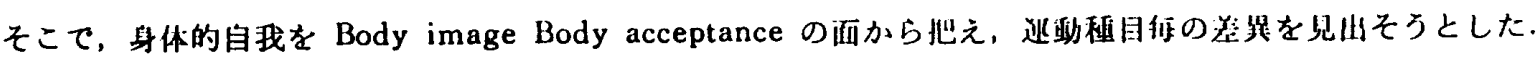

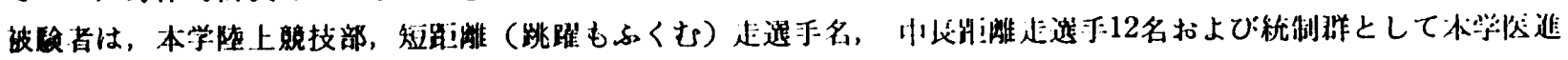
棵程学生12名である。

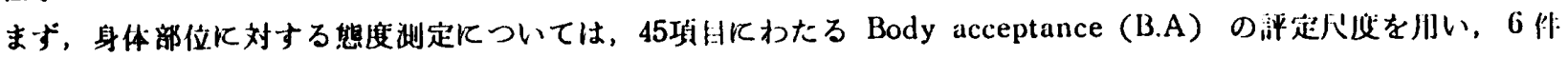

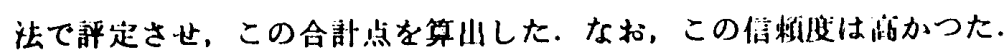

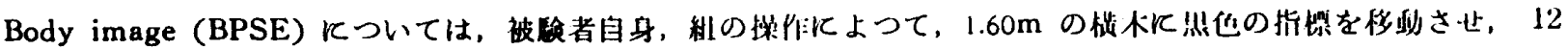
の身体部位の評㑛の辰さを示せる测定器具を用いた。

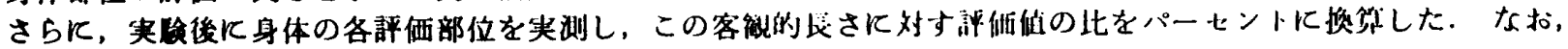
Body image Kついても㣮い信赖度が㣥られた。

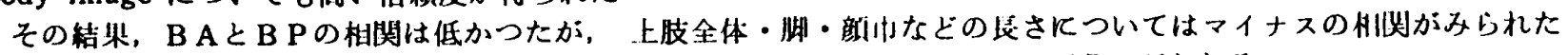

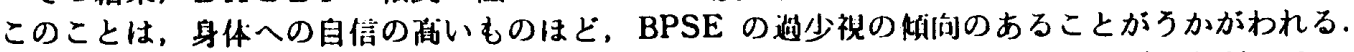

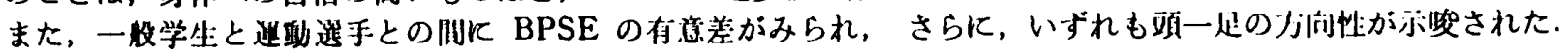

\section{8. 反応時間に閏する研究(3)一手，足の同時動作反応時間について一}

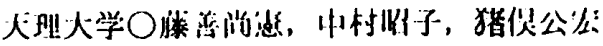

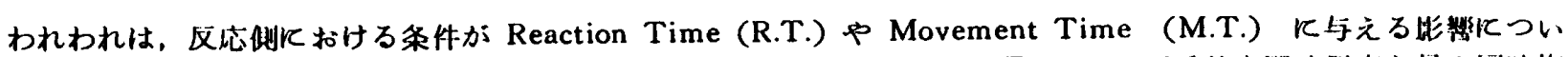

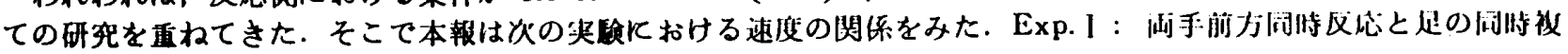
合反忘との関速性 ( 3 条件の検郡)

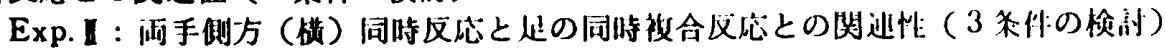

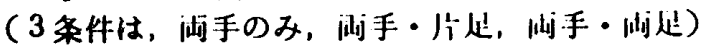

〔实臨の方法一条件亡手繶]

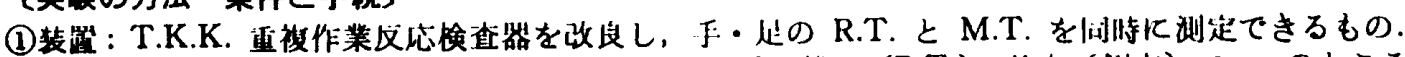

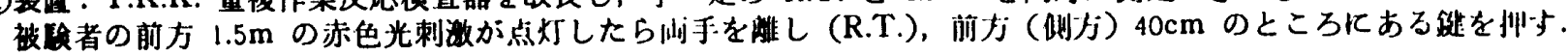
(M.T.) 4 台のデカトロンカウンターて m.s. まで晾测する.

(2)被著: 天理大学顿式テニス部冒男子12名.

(3)期日と揚所：1970年6月。実积室.

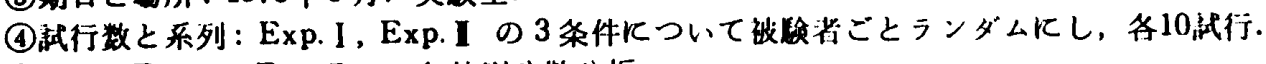

(5)整理：Exp. I，Exp.1，の条湖列分枚分析.

(結果之考察)

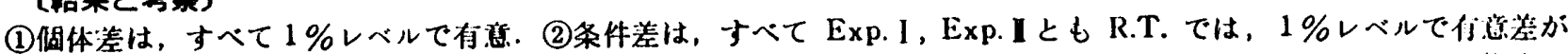

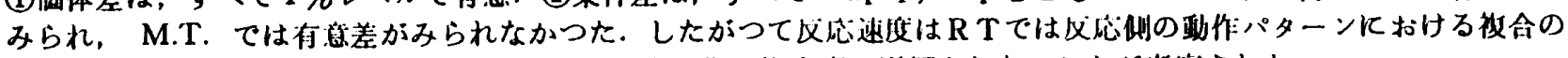

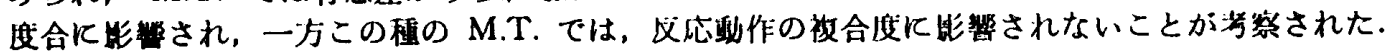

